\title{
On the Role of Media Input in the Learning of Formulaic Sequences by EFL Learners
}

\section{Didem Koban Koç E Serdar Engin Koç}

This study examined the role of media on the learning of formulaic sequences (FSs) by advanced English as a Foreign Language (EFL) learners $(n=40)$ enrolled in an English Language Teaching (ELT) program at a government university in Turkey. The learners were divided into experimental and control groups. The instrument involved clips from two American television series. Over the course of 3 weeks, the learners in the experimental group received training in 30 FSs through watching the video clips. The control group learned the FSs through training only. In order to determine the extent to which learners learned and retained the FSs, the learners in both groups were given both a posttest and a delayed posttest. Independent-samples t-tests were conducted to compare the two groups with respect to the learning and retention of FSs. The results showed that the experimental group had significantly higher rates of retention of FSs. Several pedagogical considerations regarding the teaching of FSs to English as a second language (ESL) and EFL learners are discussed.

Cette étude a examiné le rôle des médias sur l'apprentissage de formules par des étudiants avancés en anglais langue étrangère $(A L E)(n=40)$ inscrits à un programme d'enseignement de la langue anglaise dans une université publique en Turquie. Les étudiants ont été répartis en un groupe expérimental et un groupe témoin. L'apprentissage se faisait par des extraits de deux séries télévisées américaines. Pendant 3 semaines, les étudiants dans le groupe expérimental ont reçu un enseignement portant sur 30 formules par le biais de clips vidéo. Le groupe témoin a appris les formules par un enseignement standard uniquement. Afin de déterminer dans quelle mesure les étudiants avaient appris et retenu les formules, les étudiants des deux groupes ont passé un post-test et un post-test différé. Pour comparer l'apprentissage et la rétention des formules par les deux groupes, nous avons eu recours à des tests $T$ avec des échantillons indépendants. Les résultats indiquent que le taux de rétention des formules étaient plus élevé de façon significative chez le groupe expérimental. Nous discutons de plusieurs considérations pédagogiques portant sur l'enseignement de formules aux étudiants en ALS et en ALE.

KEYWORDS: formulaic sequences, video clips, EFL, ESL 
This article reports a study of teaching and learning of formulaic sequences (FSs) in an English as a Foreign Language (EFL) classroom. It seeks to answer a question that has received little attention, namely, whether learners can learn FSs through media. Formulaic language is a concept that cannot be precisely defined by scholars. One of the reasons for this is that formulaic expressions can be diverse (Schmitt \& Carter, 2004). According to Schmitt and Carter (2004), they can be short or long and used for different purposes such as expressing an idea (Look into your own backyard), declining an offer (No, thanks), and agreeing with a speaker (I hear you). They can be idioms (Hit the nail on the head), exclamations (Oh no), collocations (Take a train), proverbs (The pen is mightier than the sword), or discourse particles (Well). Wray (as cited in Schmitt and Carter, 2004) reported that over the years researchers used a variety of terms such as chunks, FSs, formulaic speech, collocations, readymade utterances, multiword units, lexical bundles, and so on to label formulaic expressions. In the present study, we adopted the term formulaic sequence because it covers a wide range of phrasal items, from exclamations to idioms. A definition of FS that has been frequently referred to in the literature was proposed by Wray (2000). Wray defined formulaic language as

a sequence, continuous or discontinuous, of words or other meaning elements, which is or appears to be, prefabricated: that is, stored and retrieved whole from memory at the time of use, rather than being subject to generation or analysis by the language grammar. (p. 465)

According to Becker (1975), FSs "give us ready-made framework on which to hang the expression of our ideas, so that we do not have to go through the labor of generating an utterance all the way out from every time we want to say anything" (p. 17).

What is unique about FSs is that they usually consist of at least two morphemes, are always used in the same form, fluently articulated (Myles, Hooper, \& Mitchell, 1998, p. 325), have meaning as whole units (Wray \& Perkins, 2000), and are commonly found in spoken and written registers. For example, Biber and Barbieri (2007) explored the extent to which lexical bundles existed in spoken and written university registers. The data were collected from spoken registers such as classroom teaching, classroom management talk, office hours, and study groups as well as from written registers such as textbooks, course management, institutional writing, and academic proses. The registers took place in disciplines such as business, engineering, natural science, social science, humanities, and education in three different levels of education (lower division, upper division, graduate) at several universities in the United States. The study found that lexical bundles were prevalent in all university registers. In addition, they were especially found to be more common in spoken registers than academic or instructional registers. Extending research that examined the frequencies with which FSs existed in different registers, Biber (2009) employed a corpus-driven approach to identify the most 
frequently used multiword patterns in conversation and academic writing. The results showed that patterns that were used in conversation were more likely to be fixed sequences, whereas patterns in academic writing tended to consist of invariable function words as well as noun phrase and prepositional phrase fragments.

FSs have been the topic of many English as a Second Language (ESL) and EFL studies in the last decades (Adolphs \& Durow, 2004; Alali \& Schmitt, 2012; AlHassan, 2016; Boers, Eyckmans, Kappel, Stengers, \& Demecheler, 2006; Dörnyei, Durow, \& Zahran, 2004; Nattinger \& DeCarrico, 2000; Skehan, 1998; Wood, 2009, 2010). The majority of empirical and theoretical work, as we will discuss in the next section, analyzed the use of FSs from sociofunctional and psycholinguistic perspectives and explored the effects of factors such as focused instruction and input on the use of FSs. Considerably less attention has been given to how FSs can be effectively taught and learned in ESL and EFL contexts. The current study was conducted to add to the existing research about the effect of media on the learning and retention of FSs and to provide recommendations as to how FSs should be taught in EFL and, in particular, Canadian ESL contexts.

\section{Literature Review}

Second language theories that support the learning of FSs include the work of Krashen (1982, 1985, 1998), Long (1980, 1996), and Schmidt (1990). Krashen $(1982,1985)$ claims that in order for the acquisition of a language to take place, learners need "comprehensible input." Thus, this makes it necessary for language teachers to provide learners with input through using a variety of materials. Inarguably, Krashen's Comprehensible Input Hypothesis has an important place in second language acquisition research; however, it is not sufficient to explain the process of second language acquisition. Long (1980, 1996) proposed the Interaction Hypothesis and argued that interaction leads to acquisition "because it connects input, internal learner capacities, particularly selective attention, and output in productive ways" (1996, pp. 451-452). Long drew attention to the conversations taking place between native and non-native speakers and argued that learners can learn a language through producing confirmation checks, comprehension checks, and clarification requests in a conversation. Another hypothesis was proposed by Schmidt (1990), who stated that learners cannot acquire a language form unless they notice it in the input. Thus, the first step in the acquisition of a language is paying attention to forms.

Studies have investigated the acquisition and usage of FSs in the light of the above-mentioned three hypotheses. Researchers analyzed the effects of focused instruction, exposure, and reviewing on oral and written usage of FSs. For example, findings from experimental research point to a link between focused instruction of FSs and learners' speaking performances. In a 
case study conducted with a Japanese learner of English, Wood (2009) investigated the effects of focused instruction of FSs on a learner's usage of English in spontaneous narratives. The learner participated in a 6-week fluency development workshop. The learner's speech was analyzed with respect to several fluency markers such as the length of runs between pauses, the speech rate, and the use of FSs. The results showed that the learner's fluency improved significantly as a result of the 6 weeks of focused instruction. The author attributed this result to the fact that the fluency workshop consisted of repetitions and practice of FSs. In a recent study, AlHassan (2016) explored the extent to which learners' academic reading and writing skills can be improved as a result of focused instruction of FSs. The participants included intermediate-level ESL learners who were enrolled in an English for Academic Purposes course at a community college in Canada. The study consisted of several stages: pretest, training session, posttest, and delayed posttest. In the training session, the instructor explicitly taught 63 FSs to the learners in 10 hours for 2 weeks. In the posttest, the learners completed a reading and writing task. They also completed a delayed posttest 2 weeks after the training period. The results showed that explicit focused instruction improved students' academic reading and writing skills.

Studies also investigated the effect of usage of FSs on fluency in a target language. For instance, Wood (2010) explored the question of whether or not the usage of FSs increased speech fluency in a study of 11 ESL learners in an English program at a Canadian university. In the study, the learners watched three silent movies twice and retold the stories in the movies. Their speech was recorded and analyzed with respect to temporal variables such as articulation and speech rate, phonation/time ratio, mean length of runs, and formula/run ratio. The results showed that there was a significant improvement in the learners' fluency.

There has also been interest in noticing and reviewing as promising methods for improving learners' usage of FSs. For example, Boers et al. (2006) conducted a study in which learners in an experimental group were exposed to authentic transcriptions of listening and reading texts. The teacher had the learners notice some FSs in English. The control group, on the other hand, focused more on grammatical and lexical issues. Afterward, oral interviews were conducted to see whether or not there was a significant difference between the two groups with regard to the usage of FSs. The results showed that the experimental group used formulaic language at a higher rate than the control group. In a recent study, Alali and Schmitt (2012) examined the effects of reviewing (oral and written) newly learned FSs such as idioms on the retention and retrieval of FSs. The study included 35 female learners who were studying at a public school in Kuwait. The authors found the reviewing technique to be effective in improving the learning of idioms. They also found that the written review technnique was more effective than the oral review. 
Some studies reported that FSs served sociofunctional and psycholinguistic purposes, which have important implications in ESL and EFL contexts. Regarding the sociofunctional factors, Skehan (1998) mentioned that learners who made use of only grammar and lexicon in their speech would never be a part of a speech community. Along the same lines, Dörnyei et al. (2004) stated that

the acquisition of a formulaic repertoire is a socially-loaded process that goes beyond mastering elements of the target language code as it also requires "tapping into" the sociocultural reality of the L2 community and incorporating elements of it into the learners' own language behavioural repertoire. (p. 87)

Studies that have been conducted with respect to social factors found that FSs enabled speakers to interact with native speakers effectively and appropriately (Wray, 1998). Further, FSs promoted fluency (Nattinger \& DeCarrico, 2000) and proficiency (Boers et al., 2006; Ohlrogge, 2009; Sonbul, 2015) and facilitated native-like speech (Pawley \& Syder, 1983; Skehan, 1998). For example, Adolphs and Durow (2004) investigated the influence of the level of social integration on the acquisition of FSs in language use. Two Chinese female learners at Nottingham University, UK, were compared to one another with regard to the use of FSs through the quantity and quality of their interaction with native speakers of English. The learners were interviewed several times over a period of seven months. The results showed that the learner who integrated relatively well with a native speaker used FSs at a significantly higher rate than the other learner, who was not as integrated as the first. Similar results were also obtained in a study conducted by Bardovi-Harlig and Bastos (2011), who found that intensity of interaction had a significant effect on the use of conventional expressions.

In another study, Dörnyei et al. (2004) analyzed the effects of individual differences, including sociocultural adaptation, on the usage of FSs. Seven international postgraduate learners at the University of Nottingham, UK, enrolled in a presessional intensive English language course were asked to participate in a series of interviews. The results showed that four learners were found to be successful in terms of using FSs. According to the authors, sociocultural adaptation played an important role on the learners' usage of the FSs.

In a recent study, Erman, Denke, Fanny, and Lundell (2015) investigated the extent to which the multiword structures (MWS) existed in the speech of a total of 30 advanced Swedish speakers of English as a second language (L2), French as L2, and Spanish as L2 and 30 native speakers. The speakers performed a role play and an online retelling task. The results showed that the non-native speakers were nativelike in their use of clausal MWSs when they were performing the role play. The authors attributed this result to the 
L2 speakers' extended length of residence in the target language community and a high degree of cultural adaptation and pragmatic knowledge.

From a psycholinguistic perspective, some scholars proposed that using FSs eased processing difficulties (Conklin \& Schmitt, 2008; Wray, 2000, 2002; Wray \& Perkins, 2000). They argued that it is easier to understand FSs because the hearer does not have to break down a sequence into discrete units. The sequence is processed as a unit, which reduces the "processing burden" (Millar, 2010, p. 131). For example, in a study conducted with 19 native and 20 non-native English speakers enrolled at the University of Nottingham, UK, Conklin and Schmitt (2008) found that both groups of speakers read the FSs more quickly than the equivalent nonformulaic phrases. The authors concluded that "FSs have a processing advantage over creatively generated language" (p. 72).

Studies also explored the effects of length, frequency, and mutual information on the processing of certain FSs. For example, in attempt to create a list of FSs to be used in academic speech and writing, Ellis, Simpson-Vlach, and Maynard (2008) selected a variety of FSs from MICASE, Michigan Corpus of Academic Spoken English, and the British National Corpus. The authors then asked native speakers and advanced ESL learners to evaluate whether the selected FSs were found in English or not and which factors (length, frequency, and mutual information) had an effect on their processing of the FSs. The results showed that native speakers' language processing was affected by mutual information of FSs when they read them for recognition of correct form and to access their pronunciation. Advanced learners, on the other hand, were affected by the frequency of FSs. The authors, therefore, suggested first teaching the most frequent FSs to non-native speakers.

Research involving the effects of media on the acquisition/learning of FSs is limited. Erdemir (2014) explored the effects of watching an American TV series on Turkish EFL learners' formulaic language usage. Sixty-six upperintermediate-level learners were categorized into experimental and control groups. The experimental group received training on formulaic language while watching the TV series whereas the control group received a traditional training of formulaic language. At the end of the treatment period, both groups were given a post and a delayed Discourse Completion Test (DCT) to check their progress and retention of the formulaic language. The results showed that both groups made progress with regard to their formulaic language use. However, the rate of the formulaic language use for the experimental group was significantly higher than that of the control group, suggesting that the experimental group was able to retain the formulaic expressions much longer than the control group. Another study involving media was conducted by Lin (2014), who investigated whether or not the use of FSs on internet television reflected the usage of FSs in daily English conversations. After comparing the distribution of FSs on internet television with 
that of the British National Corpus, Lin confirmed that the FSs used on internet television have similar frequency of usage as those used in daily speech.

Despite the reported benefits of formulaic language in ESL and EFL contexts, it appears that the focus of how to teach formulaic phrases has received comparatively less attention. Especially, little work has been conducted on the effects of using media on learning and retaining FSs in EFL and ESL classrooms. By filling this gap in the literature, the present study aims to provide useful information on vocabulary teaching to English language instructors and curriculum developers working in both EFL and ESL contexts, in Canada in particular. The study aims to address the following research questions:

1. Does exposing learners to TV series have a significant effect on EFL learners' learning of FSs?

2. Does exposing learners to TV series have a significant effect on EFL learners' retention of FSs?

3. What are the learners' perceptions about learning FSs through TV series in the classroom?

\section{Methodology}

\section{Participants}

The participants were first-year advanced-level EFL learners enrolled in the English Language Teaching (ELT) program at one of the biggest government universities in Ankara, Turkey. The ELT program is a four-year program in which learners are trained to be English language teachers. The program selects the highest achieving learners in Turkey based on the results of the nationwide university entrance exam. This exam is mandatory for all high school graduates who plan to study at a university in Turkey.

Almost all of the learners who entered the ELT program are graduates of Anatolian Teacher Training High Schools (ATTHS) in Turkey. These schools prepare learners to be teachers. In the present study, all of the learners had studied English formally for at least seven years in ATTHS before entering the ELT program. Almost all of them started learning English as soon as they entered the ATTHS around the age of 10 . The learners were exposed to about 12 hours of English language instruction per week for seven years.

After learners obtain a sufficient score at the university entrance exam to enter the ELT program, they are also required to take an English proficiency exam to show that they have sufficient knowledge of English to continue their studies in the program. The exam is prepared by the School of Foreign Languages and measures learners' reading, writing, speaking, and listening skills as well as their grammatical knowledge. Learners who pass the proficiency exam can take academic courses in their programs. Those who cannot pass the exam have to take additional English language courses for a semester or two in the School of Foreign Languages. Because all the participants in the 
present study had passed the English proficiency exam prior to the study, it can be said that they were a fairly homogeneous group in terms of their level of English proficiency.

None of the participants in the present study had been in an Englishspeaking country for more than a month. Their first language was Turkish. Overall, 40 participants, who ranged in age between 18 and 19 years, participated in the study. The majority of the participants were female due to the fact that females desire teaching more than males in Turkey ("MEB explained the number of students and teachers in Turkey," 2017).

\section{Instrument}

The instrument included clips from two American drama television (TV) series, Homeland and Shades of Blue. The reason for choosing Homeland was that it is one of the highest rated TV series (Metacritic, 92\%; Rotten Tomatoes, $87 \%)$. Shades of Blue was selected due to the fact that the main character was played by Jennifer Lopez; we believed this would increase the learners' interest in watching this TV series. When showing the clips, we made sure that the participants were not exposed to violent and obscene scenes or language that would offend the participants. We identified FSs in the third, fourth, and ninth episodes of Homeland and in the third and fourth episodes of Shades of Blue. We then consulted the British National Corpus and the Corpus of Contemporary American English to determine how frequently the FSs were used in the English language. Following AlHassan (2016), the frequencies were checked (30 occurrences per one million words). As a result, 55 FSs were retained.

\section{Experimental Design and Procedure}

At the time of the study, the participants were taking the English Vocabulary course, which is a mandatory course in the first year of the ELT program. The class met for three hours once a week for 14 weeks. The study took place during the first 1.5 hours of class time. The participants were categorized into two groups. Twenty participants were randomly assigned to the experimental group, which was exposed to the FSs through the video clips and the instructor's explicit instruction; the other 20 was assigned to the control group, which learned the FSs through the instructor's explicit instruction only.

The study consisted of several stages: pretest, treatment ( 3 weeks), posttest, and delayed posttest. At the beginning of the experiment, a pretest consisting of 55 FSs selected from both TV series was given to the participants in both groups to determine whether or not the participants knew any of the selected FSs. The participants were asked to write down either the English definition or the Turkish translations of the given FSs. The maximum score for the test was 55 points. The participants completed the test in about 20-25 minutes. After conducting the pretest, 30 target FSs (see Appendix A) were 
retained because the participants in both groups did not have any knowledge of them. The other 25 were removed from the study.

On the first day of the treatment, the instructor gave some background information about the TV series (topic, setting, and characters' backstories) to the participants in the experimental group because none of the participants had previous knowledge about the series. Some participants reported that they had heard the names of the series before but had never watched them. The treatment lasted for 3 weeks. In each week, the participants were exposed to 10 clips from the TV series. Each of the clips had one FS. The instructor made sure that the participants were exposed to each clip long enough to understand the context in which each FS was used. Each clip lasted an average of 10 seconds. The participants were provided with a list of $10 \mathrm{FSs}$ for each week. After watching each clip, the instructor drew the participants' attention to the FS and provided its definition.

The instructor also gave a list of 10 FSs to the participants in the control group each week and provided the definition of each FS and the context in which each can be used. At the end of each session, the instructor asked the participants in both groups to work in pairs and create conversational scenarios using each FS that they learned. The only difference between the experimental and the control group was that the participants in the experimental group were exposed to the video clips.

A week after the treatment period, a posttest was administered to all participants, followed by a delayed posttest after another week. The purpose of the posttest was to determine the extent to which the participants learned the FSs. The delayed posttest was conducted to determine the degree of retention of the FSs. The posttest and the delayed posttest consisted of the same 30 target FSs. The maximum score for each test was 30 points. The participants were asked to write down either the English definition or the Turkish translations of the given FSs in both tests. The participants completed both tests in about 20 minutes.

Immediately after the delayed posttest, the researchers conducted semistructured interviews with seven participants (four females and three males) from the experimental group to obtain their opinions about learning FSs through TV series. Each interview lasted for about 5-10 minutes and addressed several aspects including (a) the participants' perceptions of learning FSs through TV series, (b) the advantages and/or disadvantages of learning FSs through TV series, (c) the participants' perceptions of how FSs were taught in high schools in Turkey, and (d) whether or not the participants would teach English FSs through media when they became teachers (see Appendix B for interview questions). During the interviews, the researchers made sure that the participants understood all the questions correctly by paraphrasing them when necessary. The participants answered all the questions willingly, in an open manner. After the interviews, the participants' comments were transcribed and translated into English by the researchers. The translations were 
checked by two experts in the Department of Translation and Interpretation Studies at a government university in Turkey.

This research employed both quantitative and qualitative methods of data analyses. The quantitative data were analyzed through the Statistical Package for the Social Sciences (SPSS) for Windows, Version 23. To address the first research question, which aimed to examine the effects of using TV series on the learning of FSs, an independent-samples $t$-test was performed. To address the second research question, which explored the relationship between exposure to TV series and retention of FSs, another independent-samples $t$-test was conducted. In the next section, we discuss the results.

\section{Results}

\section{Quantitative Analysis}

The results of independent-samples t-test of the two groups on the posttest can be seen in Table 1. Exposure to the FSs constituted the independent variable, and the participants' scores on the posttest served as the dependent variable.

\section{Table 1}

Results of Independent-Samples $t$-Test of the Two Groups on the Posttest

\begin{tabular}{llrrrrrr}
\hline & Groups & $N$ & $M$ & $S D$ & $M D$ & $t$ & $\mathrm{df}$ \\
\hline \multirow{3}{*}{ Posttest } & Control group & 20 & 11.80 & 5.99 & & & \\
& & & & & -1.95 & -1.15 & 38 \\
& Experimental group & 20 & 13.75 & 4.55 & & & \\
\hline
\end{tabular}

Table 1 shows that the learning rate for the experimental group $(M=13.75$, $S D=4.55)$ was higher than that of the control group $(M=11.80, S D=5.99)$. However, this difference was not significant. To determine whether there was a statistically significant difference between the groups regarding the retention of the FSs, another independent-samples $t$-test was performed on the delayed posttest. Table 2 presents those results.

Table 2

Results of Independent-Samples $t$-Test of the Two Groups on the Delayed Posttest

\begin{tabular}{llrrrrrr}
\hline & Groups & $N$ & $M$ & $S D$ & $M D$ & $t$ & $\mathrm{df}$ \\
\hline \multirow{3}{*}{ Delayed posttest } & Control group & 20 & 8.35 & 4.41 & & & \\
& & & & & -2.65 & $-2.04^{*}$ & 38 \\
& Experimental group & 20 & 11.00 & 3.72 & & & \\
\hline
\end{tabular}

${ }^{{ }^{*}} p=.05 ; d=.02$ 
As the results show, the differences in the retention of the FSs between the two groups was statistically significant $(t=-2.04, p=.05)$. The experimental group $(M=11.00, S D=3.72)$ retained the FSs at a higher rate than the control group $(M=8.35, S D=4.41)$. Cohen's effect size value $(d=.02)$ suggested a small significance.

\section{Qualitative Analysis}

\section{Individual İnterviews}

In this section, we present the results of data analyses related to the interviews conducted with seven participants. The first interview question was related to the participants' overall experiences with learning the FSs through the TV series in this class. In general, the participants' experiences have been positive. The following excerpts illustrate this:

I really liked learning idioms and expressions in the classroom. Unfortunately, we were not even exposed to them in high school. I enjoyed the class even much more when we learned them through the TV series. (Speaker A, female, 3/20/2017)

It was great that we saw how idioms and collocations were used in the TV series. I wish we had learned them like this since the beginning of the semester. (Speaker B, male, 3/20/2017)

These were the usages that I have always heard on TV but could not understand. It was good that you showed and explained them to us. (Speaker C, female, 3/20/2017)

The second interview question was concerned with the participants' opinions about the advantages and disadvantages of learning FSs through the TV series. Almost all the participants mentioned the advantages of seeing how FSs were used in visual contexts. The following excerpts exemplify these findings:

I learned English through TV series anyway. I can say that it is easier to remember words and expressions when you hear them on TV. When you hear an idiom, you remember the context in which it is used and when you see a context, you remember the idiom that has been used in that particular context. When you think about the context and the idiom together, you can easily remember the meaning of the idiom. (Speaker D, female, 3/20/2017)

I find it really useful when instructors use video materials in the classroom. This way we can see how language is used in context. For example, we can get a deeper understanding of how vocabulary items or phrases can have different meanings in different contexts. 
You cannot learn the meanings of idioms and expressions by only reading and analyzing written texts. You have to see how they are used in context. (Speaker F, female, 3/20/2017)

Speaker E emphazised the fact that watching TV series also helps with retention of vocabulary items.

This [watching TV series] is actually something that I have always done to learn new vocabulary items. Whenever I watched TV series, I took notes of new words, expressions and idioms. This way, not only I learned a lot of new items, but also I was able to remember them even after a long time. (Speaker E, male, 3/20/2017)

Regarding the third question, which is related to the participants' learning experiences in high school, almost all the speakers commented on the fact that the English lessons were usually grammar-oriented. The participants reported that they were never really exposed to FSs in the lessons. The participants, therefore, criticized the current situation in state high schools in Turkey. This is evident in the following comments:

Instructors just taught grammar and gave grammar tests to prepare students for the university entrance exam. We did not do any speaking or writing activities. Instructors did not use a variety of methods and materials. They just used one book. (Speaker G, male, 3/20/2017)

We were not taught any idioms or expressions in high schools. We just did grammar exercises to pass the university entrance exam. (Speaker D, female, 3/20/2017)

At the beginning of each school year, our instructors would tell us that we would learn two idioms each week and for this, they would ask us to buy a small notebook to take notes in them. They would be very enthusiastic about it. But after a few weeks, they would stop teaching idioms. (Speaker F, female, 3/20/2017)

Finally, the fourth question explored whether the participants would use TV series to teach FSs to their students when they became teachers. All the participants reported that they would use TV series when teaching FSs in their classes. The following extracts provide examples for this statement:

After I become a teacher, my dream is to teach English to my students through showing them TV series. I believe that every teacher should do the same. It is a shame that we do not make use of technology in schools. (Speaker E, female, 3/20/2017)

I would choose a TV series appropriate for my students and have them take notes of FSs while they watch it. (Speaker F, female, 3/20/2017) 
I would teach FSs from time to time. For example, if the topic for the week is "Nature," then I would teach my students the FSs that are related to the Nature. I would like to use media too because you see how people pronounce FSs and how they are used in context. (Speaker F, female, 3/20/2017)

\section{Discussion and Conclusion}

In this study, we examine the role of media on the learning and retention of FSs by advanced EFL learners enrolled in an ELT program at a government university in Turkey. Our study addresses a gap in extant formulaic language research. Extending research that has examined the use of formulaic language in other settings (Adolphs \& Durow, 2004; Dörnyei et al., 2004; Ellis et al., 2008), we used TV series to teach FSs to EFL learners. In the first research question, we asked whether exposing learners to TV series had a significant effect on their learning of FSs - that is, the extent to which the learners succeeded in learning the FSs as a result of their exposure to TV. Although the learning rate of the learners who were exposed to the TV series was higher than those who were not exposed to the video clips, the difference between the two groups was not statistically significant. One possible explanation for this result is that the Turkish educational system is based on memorization and Turkish learners can be very good at memorizing the definitions and meanings of many vocabulary items. It may be the case that the learners in the control group memorized the definitions of the FSs very well.

The second research question explored whether exposing EFL learners to TV series had a significant effect on their retention of FSs. Our study yielded a significant difference between the experimental and the control group. Noticing how the FSs were used among real speakers in visual contexts probably facilitated a higher chance of successful retention of the FSs by the learners in the experimental group. Although we need to be cautious in comparing our findings to those of previous studies because of the different methods used, it is worth noting that our finding is in harmony with the results of previous studies (Erdemir, 2014; Schmidt, 1990; Wood, 2002). According to Wood (2002), instructors should ensure that learners are repeatedly exposed to real-time conversations so that they can retain FSs as single items. The finding also seems to be in line with the results provided by Erdemir (2014), who found an influence of media on the retention of FSs. The results are also in support of Schmidt's (1990) Noticing Hypothesis that emphasized the role of attention and awareness in adult second language acquisition. It can be said that seeing how the FSs were used in visual contexts in the TV series helped the learners in the experimental group to retain the FSs longer than those in the control group.

The third research question concerned the learners' perceptions of learning FSs through the TV series. As evidenced in the data, the learners maintained 
positive attitudes toward learning the FSs through the TV series, mentioned the importance of seeing how the FSs were used in contexts, and criticized the current English language teaching situation in state high schools in Turkey by discussing how the teaching and learning of FSs were neglected in English lessons. The participants' responses seem to support a recent comprehensive study conducted by the British Council and the Economic Policy Research Foundation of Turkey in state high schools in Turkey (British Council Project Team, 2015). According to the study, learners' competence level in speaking found to be very limited even after 1000+ hours of English classes in high schools. Learners fail to communicate in English because classrooms are still teacher-centred and school administrators and teachers follow a grammarbased approach. Finally, the learners also reported that they would use TV series when teaching FSs in their classes.

\section{Implications for the Canadian ESL Context}

Given these results, the teaching of English in materials and practices should change its area of focus. Rather than only presenting grammatical structures in English, English language teachers and curriculum developers should, first of all, incorporate the teaching of FSs into the lessons and help learners become aware of a variety of FSs through appropriate input. One implication of our study for classroom instructional practice in the Canadian ESL context is that teachers should develop an understanding for learners who cannot always find opportunities to interact with native speakers of English. Some international learners get by in their native language because they tend to live and spend time with speakers with the same first language (L1). This being the case, such learners may not know how certain structures such as FSs are used in the English language and thus use FSs at a lower rate than native speakers (Blum-Kulka \& Olshtain, 1986; Fan, 2009). Therefore, it is essential that instructors raise learners' awareness of the most frequently used FSs in English and involve learners in comprehending and producing FSs in appropriate contexts. One way to achieve this can be the use of media. Instructors can bring in movies or TV series and help learners notice how FSs are used among speakers. However, when exposing learners to FSs in media, instructors should make sure that the way FSs are used in media correspond to how they are used in real life. Frequent exposure to and noticing of FSs in visual contexts and multiple opporunities to practice in small groups and role-play exercises should enable learners to acquire and use them over time.

Another implication has to do with comparing learners' L1 with the English language in terms of the usage of FSs. Given the fact that learners' L1 can negatively influence the use of FSs in English (Fan, 2009), it can be beneficial to draw learners' attention to meaning similarities between the FSs in the learners' native language and English. Although there can be syntactic differences between the two languages, learners may be able to retrieve FSs similar in meaning much faster than those different in meaning. These suggestions 
are important for ESL and EFL classrooms, where learners do not find opportunities to interact with native speakers of English and access language input in visual contexts.

\section{Limitations}

It is important to mention the limitations of this study that need to be addressed in future research. The first limitation is the participant sample. It should be noted that the EFL group consisted of first-year advanced learners who are expected to be English language teachers in three years. It can be said that they had a high metalinguistic understanding of structures in English. As a consequence, generalizing the findings to other groups of EFL or ESL learners may not be appropriate. In this light, it is important for future studies to include learners with different levels of proficiency.

The second limitation has to do with the learners' production of the FSs in the activities. Although the learners in both groups worked in pairs to create conversations that included the FSs and then shared their conversations with the class, a future study could just focus on spontaneous oral production.

Another limitation concerns the fact that the participants were exposed to scripted speech. Although some scholars argue that scripted speech is determined by the underlying rules, linguistic principles, and conversational conventions of naturally occurring speech and that scripted speech and naturally occurring speech share common features (Dynel, 2011; Richardson, 2010), scripted speech tends to be artificial, carefully constructed, and inauthentic. For this reason, future research can also include recordings of everyday speech among native speakers of English.

\section{Authors}

Didem Koban Koç is an assistant professor in the Department of English Language Teaching at Hacettepe University, Turkey. She received a PhD degree in Linguistics from the City University of New York in 2009. Her current interests include second language acquisition and bilingualism.

Serdar Engin Koç is an assistant professor in the Department of Computer Education and Instructional Technologies at Başkent University, Turkey. He received his PhD degree in Computer Education and Educational Technologies from Middle East Technical University in 2009. His interests include teaching with games, autonomy, distance education, and programming.

\section{References}

Adolphs, S., \& Durow, V. (2004). Social-cultural integration and the development of formulaic sequences. In N. Schmitt (Ed.), Formulaic sequences: Acquisition, processing, and use (pp. 107126). Amsterdam, Netherlands: John Benjamins.

Alali, F. A., \& Schmitt, N. (2012). Teaching formulaic sequences: The same as or different from teaching single words? TESOL Journal, 3(2), 153-180. https://doi.org/10.1002/tesj.13

AlHassan, L. (2016). Learning all the parts of the puzzle: Focused instruction of formulaic sequences through the lens of activity theory. In H. M. McGarrell \& D. Wood (Eds.). Contact: Special Research Symposium Issue, 42(2), 44-65. Toronto: TESL Ontario. Retrieved from http:// www.teslontario.net/uploads/publications/researchsymposium/ResearchSymposium 2016. pdf 
Bardovi-Harlig, K., \& Bastos, M. T. (2011). Proficiency, length of stay, and intensity of interaction and the acquisition of conventional expressions in L2 pragmatics. Intercultural Pragmatics 8 , 347-384. https://doi.org/10.1515/iprg.2011.017

Becker, J. (1975). The phrasal lexicon. Cambridge, MA: Bolt, Beranek, and Newman.

Biber, D. (2009). A corpus-driven approach to formulaic language in English: Multi-word patterns in speech and writing. International Journal of Corpus Linguistics, 14(3), 275-311. https:// doi.org/10.1075/ijcl.14.3.08bib

Biber, D., \& Barbieri, F. (2007). Lexical bundles in university spoken and written registers. English for Specific Purposes, 26(3), 263-286. https://doi.org/10.1016/j.esp.2006.08.003

Blum-Kulka, S., \& Olshtain, E. (1986). Too many words: Length of utterance and pragmatic failure. Studies in Second Language Acquisition, 8(2), 165-179. https://doi.org/10.1017/ S0272263100006069

Boers, F., Eyckmans, J., Kappel, J., Stengers, H., \& Demecheleer, M. (2006). Formulaic sequences and perceived oral proficiency: Putting a lexical approach to the test. Language Teaching Research 10, 245-261. https://doi.org/10.1191/13621688061r195oa

British Council Project Team. (2015). The state of English in higher education in Turkey. Retrieved from https://www.britishcouncil.org.tr/sites/default/files/he_baseline_study_book_web_-son.pdf

Conklin, K., \& Schmitt, N. (2008). Formulaic sequences: Are they processed more quickly than non-formulaic language by native and non-native speakers. Applied Linguistics, 29, 72-89. https://doi.org/10.1093/applin/amm022.

Dörnyei, Z., Durow, V., \& Zahran, K. (2004). Individual differences and their effects on formulaic sequence acquisition. In N. Schmitt (Ed.), Formulaic sequences: Acquisition, processing, and use (pp. 87-106). Amsterdam, Netherlands: John Benjamins.

Dynel, M. (2011). Stranger than fiction? A few methodological notes on linguistic research in film discourse. Brno Studies in English, 37(1), 41-61. https://doi.org/10.5817/BSE2011-1-3

Ellis, N. C., Simpson-Vlach, R., \& Maynard, C. (2008). Formulaic language in native and second language speakers: Psycholinguistics, corpus linguistics, and TESOL. TESOL Quarterly, 42(3), 375-396. https://doi.org/10.1002/j.1545-7249.2008.tb00137.x

Erdemir, F. B. (2014). The effects of watching American TV series on tertiary level EFL learners' use of formulaic language (Unpublished master's thesis). Bilkent University, Ankara, Turkey.

Erman, B., Denke, A., Fant, L., \& Lundell, F. F. (2015). Nativelike expression in the speech of long-residency L2 users: A study of multiword structures in L2 English, French, and Spanish. International Journal of Applied Linguistics, 25(2), 160-182. https://doi.org/10.1111/ijal.12061

Fan, M. (2009). An exploratory study of collocational use by ESL students: A task based approach. System, 37(1), 110-123. https://doi.org/10.1016/j.system.2008.06.004

Krashen, S.D. (1982). Principles and practice in second language acquisition. Oxford, UK: Pergamon.

Krashen, S. (1985). The input hypothesis: Issues and implications. New York, NY: Longman.

Krashen, S. (1998). Comprehensible output. System, 26, 175-182. https://doi.org/10.1016/S0346251X(98)00002-5

Lin, P. M. S. (2014). Investigating the validity of internet television as a resource for acquiring L2 formulaic sequences. System, 42, 164-176. https://doi.org/10.1016/j.system.2013.11.010

Long, M. (1980). Input, interaction and second language acquisition (Unpublished doctoral Dissertation). University of California, Los Angeles.

Long, M. (1996). The role of the linguistic environment in second language acquisition. In W. Ritchie \& T. Bhatia (Eds.). Handbook of second language acquisition (Vol. 2, pp. 413-468). San Diego, CA: Academic Press.

Millar, N. (2010). The processing of malformed formulaic language. Applied Linguistics, 32, 129148. https://doi.org/10.1093/applin/amq035

Ministry of Education explained the number of students and teachers in Turkey. (March 31, 2017). Retrieved from https://translate.google.com.tr/translate?hl=en\&sl=tr\&u=http:// www.borsagundem.com/haber/meb-turkiyedeki-ogrenci-ve-ogretmensayisiniacikladi/1181454\&prev=search 
Myles, E., Hooper, J., \& Mitchell, R. (1998). Rote or rule? Exploring the role of formulaic language in classroom foreign language learning. Language Learning, 48(3), 323-363. https://doi. org/10.1111/0023-8333.00045

Nattinger, J., \& DeCarrico, J. (2000). Lexical phrases and language teaching. Shanghai: Shanghai Foreign Language Education Press.

Ohlrogge, A. (2009). Formulaic expression in intermediate EFL writing assessment. In R. Corrigan, E. Moravcsik, H. Ouali, \& K. Wheatley (Eds.), Formulaic language: Acquisition, loss, psychological reality, and functional explanations (Vol. 2, pp. 375-386). Philadelphia, PA: John Benjamins.

Pawley, A., \& Syder, F. H. (1983). Two puzzles for linguistic theory: Nativelike selection and nativelike fluency. In J. C. Richards \& R. Schmidt (Eds.), Language and communication (pp. 191-225). London, UK: Longman.

Richardson, K. (2010). Television dramatic dialogue: A sociolinguistic study. Oxford, UK: Oxford University Press.

Schmidt, R.W. (1990). The role of consciousness in second language learning. Applied Linguistics 11, 129-58. https://doi.org/10.1093/applin/11.2.129

Schmitt, N. \& Carter, R. (2004). Formulaic sequences in action: An introduction. In N. Schmitt (Ed.), Formulaic sequences: Acquisition, processing, and use (pp. 1-22). Amsterdam, Netherlands: John Benjamins.

Skehan, P. (1998). A cognitive approach to language learning. Oxford, UK: Oxford University Press.

Sonbul, S. (2015). Fatal mistake, awful mistake, or extreme mistake? Frequency effects on off-line/ on-line collocational processing. Bilingualism: Language and Cognition, 18, 419-437. https:// doi.org/10.1017/S1366728914000674.

Wood, D. (2002). Formulaic language in acquisition and production: Implications for teaching. TESL Canada Journal, 20(1), 1-15. https://doi.org/10.18806/tesl.v20i1.935

Wood, D. (2009). Effects of focused instruction of formulaic sequences on fluent expression in second language narratives: A case study. Canadian Journal of Applied Linguistics, 12(1), 39-57.

Wood, D. (2010). Formulaic language and second language speech fluency: Background, evidence and classroom applications. New York, NY: Continuum.

Wray, A. (1998). Protolanguage as a holistic system for social interaction. Language and Communication, 18, 47-67. https://doi.org/10.1016/S0271-5309(97)00033-5

Wray, A. (2000). Holistic utterances in protolanguage: The link from primates to humans. In C. Knight, M. Studdert-Kennedy, \& J. R. Hurford (Eds.), The evolutionary emergence of language: Social function and the origins of linguistic form (pp. 285-302). Cambridge, UK: Cambridge University Press.

Wray, A. (2002). Formulaic language and the lexicon. Cambridge, UK: Cambridge University Press. Wray, A. \& Perkins, M. R. (2000). The functions of formulaic language: An integrated model. Language and Communication 20, 1-28. https://doi.org/10.1016/S0271-5309(99)00015-4 
Appendix A. Selected FSs from the TV Series

$\begin{array}{lll}\begin{array}{ll}\text { Shut down } \\ \text { Hold oneself apart }\end{array} & \begin{array}{l}\text { To put out feelers } \\ \text { Draw a line in the sand } \\ \text { One's call }\end{array} & \begin{array}{l}\text { Off-the-book } \\ \text { It's on you }\end{array} \\ \begin{array}{ll}\text { Break bread } & \text { Sub in }\end{array} \\ \text { Hedge one's bets } & \text { Get a load of this/that } \\ \text { To bring an indictment } & \text { Single out } & \text { Tap out } \\ \text { Word in somebody's ear } & \text { I hear you } & \text { To get cold feet } \\ \text { To get on the wrong foot } & \text { Send a tailspin } & \text { To get somebody's head back in the game } \\ \text { Pick one's brain } & \text { Hook somebody up } & \text { Look at one's own backyard } \\ \text { Hard to come by } & \text { Shake down } & \text { To give a heads up }\end{array}$

\section{Appendix B. Guiding Interview Questions}

1. What is your experience with learning the FSs through the TV series in this class?

2 What do you see as advantages and/or disadvantages of learning FSs through TV series?

3. Were you ever exposed to media in your classes when you were learning FSs? What methods did your English language teachers use in high school?

4. When you become a teacher, would you consider using TV series in teaching FSs to your students? 